\title{
ETHICAL APPROACH TO CORPORATE REDUNDANCY PROCESSES
}

\author{
Juan Ignacio Martin-Castilla \\ Patricia Ruiz-Martin
}

\begin{abstract}
This study is an attempt to define an illustrative path for a holistic cognitive exploration in a structured and systematic manner of redundancy process from an ethical approach.
\end{abstract}

The systematic approach tries to make the organization aware of the different possible impacts on people along the whole restructuring process. As a consequence, this research is focused on the conceptual analysis of the different possible ethical considerations throughout the sequential stages within a prototype redundancy process.

The findings are the result of logical qualitative analysis through twenty seven in-depth interviews: to people facing redundancy, Human Resources Managers and remaining employees of three different multinational companies. Additionally there was carried out three focus groups, as well as the revision of academic literature.

This article shows that the ethical character of an organization represents the best perspective for an optimum interpretation within a realistic context, exploring cognitively the possible impacts and effects that its actions have or may have on individuals.

\section{Redundancy in the context of strategic management}

There is no doubt that restructuring is a strategic action which, on occasions, seems an inevitable part of the competitive processes between organizations. However, the way in which these critical situations are managed ought to provide a clear demonstration of an organization's ethical character and its management, who should be aware of the consequences of their actions on different stakeholders. Boatright (2007) suggest that the selection of corporate goals and the evaluation of outcomes should be not solely by the criteria of profitability and organizational well-being but by ethical standards or judgments of social desirability".

\section{Juan Ignacio Martin-Castilla}

Business Organization Department;

Universidad Autónoma de Madrid

Madrid, Spain

\section{Patricia Ruiz-Martin}

Business Organization Department;

Universidad Autónoma de Madrid

Madrid, Spain
According to Denis and Kruse (2000), there many wellestablished studies on determinants of corporate announcements of downsizing On the other hand, there is a need to understand "how managerial attitudes towards ethics and social responsibility influence business decisions" (Etheredge, 1999). According to Kozlowski et al. (1993), there is a need for a "comprehensive theory that addresses downsizing processes across levels of conceptualization and over time". Unfortunately, little is known about the importance of ethical approaches to downsizing processes (Datta et al. 2010).

Although in recent years, given the focus on the three stakeholders groups the company must satisfy if it is to survive and prosper: customers, employees and shareholders" (Hill and Jones 2001), the extremely important role of people in organizational strategy seems to have been almost unanimously accepted, there are frequently cases (more than one would hope in an ethically mature society) where corporate restructuring ends up in processes that are "corporately irresponsible". On these occasions, organizations may seem to have forgotten the obligations that go hand in hand with employing staff. In the tension between management's obligations to investors and its obligations to this staff., then may be examples where the human essence of individuals is imperilled, making it difficult to define the frontier where their position changes from having the right to be considered an integral part of the organization and participate in its culture to a new status where they are stripped of their corporate identity.

Similarly, the way that individuals reach positions with great responsibility in many of these organizations is increasingly worrying and highly damaging to society. Although they may have a high level of technical knowledge of the business or profession, they may be immature in ethical and human terms. Some are people with cognitive failings in the area of ethics who have no awareness of the repercussions of their decisions and behavior on the people for whom they are responsible. We should be aware of the utilitarian vision of human beings that some managers may have. These managers might be unconscious about the special obligations that their role implies towards different stakeholders, and in this case towards their own employees, who should not be considered as a resource, but as people for whom the organization must also consider as a key agent for the success of their global strategic objectives.

It is true that a company is not an NGO, but nor should it become the cannibal which, in order to survive in a given 
scenario, cuts off some of its limbs. Perhaps, part of its managers is largely responsible of this critical situation, which has a key impact on one's perceptions of whether the action is ethical (Lange and Washburn 2012). It is even more certain that in a free market, at the same time as it seeks to fulfil its mission and to carry out the company's particular activity, it must also endeavour to build for the common good of society,. This means that it must embrace a set of essential social and moral objectives. Or does a company only have droit de seigneur over the resources society makes available with no obligations to make provisions for welfare.

It may be that in specific circumstances a company feels it must restructure itself as a result of changing its strategy to meet a number of strategic challenges, increased automation, or may be as a result of a poor business results or on the other hand a merger process. It is important to analyse which decisions and individuals have led to this situation. A restructuring of this kind may consist in a reduction in the company's size and/or scope, a modification of its structure, or modifying its portfolio of businesses or its resources and abilities to meet strategic requirements.

In this study we will focus on restructuring exercises that lead to redundancies or a reduction in workforces.

According to Hill and Jones (1996), possible generic reasons for restructuring include:

1. Ineffective leadership.

2. Too much growth.

3. Inadequate management controls.

4. High costs arising from low employee productivity, demotivation, lack of economies of scale etc.

5. New entry by competitors.

6. Unexpected changes in demand.

7. Organizational inertia or a lack of flexibility.

An analysis of these reasons for restructuring suggested by the above authors, highlights two main groups of motives: those arising from changes in the company's strategic environment and those arising from internal results and the administration and management of the company. This is logical given that the strategy adopted by an organization must respond to different challenges defined by certain external and internal factors. The external factors defining the strategic challenges include both the different generic and specific variables of the environmental and the competition created by the different competitive forces of that environment. For their part, internal factors influencing the strategic challenge arise from the organization's strategic objectives together with the resources and abilities at its service to achieve them.

Confronted with external factors, an organization must continually adapt its planning and update its strategy, making use of the correct tools to identify the different factors characterising its environment. This requires appropriate leadership and a qualified management team and a high degree of responsibility when it comes to decision-making. Leadership that is aware of the significance of its decisions and their impact on stakeholders, not only shareholders or owners, management or customers, but also employees, suppliers and other allies and also on society. And it must do this with a sustainable perspective on the value contributed to these stakeholders and the balance between different interests. In this way, management must be legitimised from day-to-day and both the organization and society must demand that the leaders of these organizations accept responsibility for their decisions and their outcomes. Of course, the management of the company has its own rights but it must also bear its obligations and responsibilities in the light of results achieved - even more so when these affect a group of stakeholders who are mainly amongst the most vulnerable.

For their part, and in relation to internal factors that characterise the strategic challenge, the strategy must be aligned and consistent with the organization's strategic objectives together with the resources and abilities that it has to achieve them. These strategic objectives must be in line with the organization's vision, mission and values and it should not be forgotten that they balance the interests of different stakeholders or that they must correspond to its resources and abilities that enable them to be achieved. We can also observe at this point that directors should feel a deep sense of responsibility when defining strategic objectives and not forget that maximising profits is just one of many objectives that must be balanced within the general framework of maximising the value contributed by the organization to its different stakeholders. Moreover, these objectives must be maximized in a sustainable manner, with people having priority over resources. Similarly, while resources are a means of achieving an end or objective and whose value may appreciate over time, people are an end in themselves and should never be placed on the same level as resources. It should be possible to revalue them, improving qualifications and employability.

It is essential to analyse risks for individuals fairly when implementing a strategy and not to focus purely on economic factors.

Management may be responsible for the majority of generic motors for restructuring, both as a consequence of ineffective management, inadequate controls or failure to anticipate market developments and a lack of values or in lethargy. In addition, we can highlight in certain shameful cases - more than we might like to think - reasons linked to discrimination on various grounds (gender, maternity or sickness leave, physical appearance, age, political or due to harmful individual value judgments that have more to do with personal relationships with subordinates).

Managers should be responsible not only for unleashing and implementing restructuring itself but also for the stages prior to its implementation via the decision to choose an employee, people management and also the development, facilitation and improvement of their employability.

\section{Methodology}

This paper is focused on the conceptual analysis of the different possible considerations throughout the sequential stages within a prototype restructuring process 
The findings of this study are the result of logical qualitative analysis through twenty seven in-depth interviews: to people facing redundancy, Human Resources Managers and remaining employees of three different multinational companies. Additionally there was carried out three focus groups, as well as the revision of academic literature. As a result of a deductive approach, bases on literature and the opinion of HR managers, this research stated six stages in the redundancy process. After that, in a first round of interviews, participants outlined the main considerations which would allow an organization to evaluate its corporate responsibility during each stage. Next, we sent a list of items to a panel, and after three focus groups with seventeen experts in business ethics we refine the items or ethical considerations that the organization may bear in mind in every stage.

\section{The Process of Redundancy and Its Aims}

For the purpose of analysing corporate responsibility throughout the process of restructuring an organization, we can state the following 6 stages:

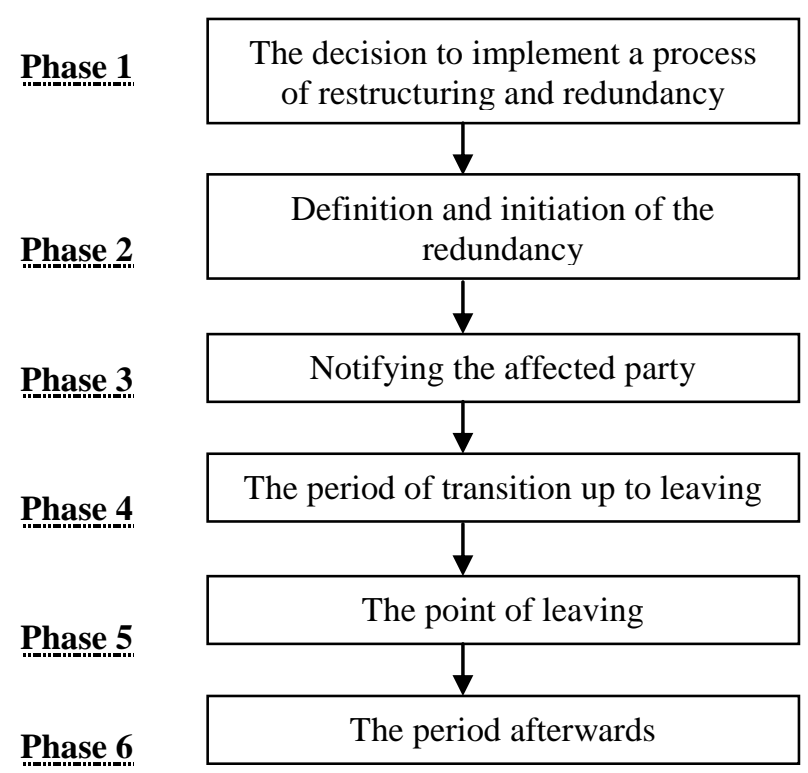

Figure 1. Path in the process of restructuring

These stages are analysed in detail below.

\section{A. The decision to implement a process of restructuring and redundancy.}

The possible considerations which would allow an organization to evaluate its corporate responsibility during this stage may be as follows:

- What should the organization do?

- Does the decision raise moral doubts?

- Is the organization treating people as ends in themselves or as means?

- What is the possible harm that the decision may cause people and their environment and also the organization and remaining employees?

- How has this situation come about?
- Is the decision coherent and consistent with achieving the objectives?

- Is the management responsible for the situation that has arisen?

- Have the management responsible for the situation that has arisen been asked to take responsibility?

- Are there alternatives to redundancy?

- Are there other alternatives to redundancy which create a balance in maximising the value to all stakeholders and which support the sustainability of the business?

- Are these alternatives, albeit long-term, fairer and less traumatic?

- Are these alternatives more ethical?

- Are the organization and its management proud of the decision?

- Does the decision comply with employment law?

- Would those responsible for the decision like to be treated in the same way should they find themselves in the same circumstances?

- Does the decision contribute to the sustainability of the organization and relationships with different stakeholders?

- Are the organization's managers required to show particular sensitivity and awareness about the possible repercussions of their decisions and behaviour on the sustainability of the business?

- Could the decision damage the sense of belonging and commitment of the organization's remaining employees?

Does the decision sacrifice the quest for the welfare of individuals in favour of maximising profits?

- Is the decision consistent with the values and code of conduct promulgated by the organization?

- Are the managers particularly sensitive and devoted to the welfare of their employees and are they their main champions?

- Does the organization equate its interests with those of its employees?

- Has the possible impact of the decision on quality of service to customers and on the organization's image and reputation been analysed?

Is the selection process for redundancy based on fairness and objectivity and, therefore, nondiscriminatory?

\section{B. Definition and initiation of the redundancy process}

Once a decision to implement the restructuring process with consequent redundancies has been taken, the organization enters into a phase of defining and initiating the redundancy process. During this stage, the following cognitive aspects may be considered:

- Has minimising the harm to or negative impact on affected individuals been considered when defining the redundancy process?

- Is the process consistent with the values, ethical principles and codes of conduct of the organization?

- Has the fact that individuals are affected been considered when defining the redundancy process and have actions been taken accordingly? 
- Have people being considered as individuals, and as ends in themselves, when defining the redundancy process?

Have relevant activities been put in place aimed at mitigating and relieving the impact of redundancy on individuals, such as assistance with jobseeking (outplacement) and other options?

Is the redundancy process transparent, in accordance with legal and judicial principles, rigorous and consistent with the organization's values?

Is there a communication plan aimed both at those affected and the rest of the organization?

Has the personal and professional integrity and honour of those affected been preserved?

Has the redundancy process been designed in such a way that it safeguards the economic and moral rights and interests of those affected?

- Has the redundancy process been designed in such a way that it safeguards the rights of clients and the sustainability of relationships with the organization?

Has the redundancy process been designed in such a way that it safeguards the organization's reputation and the sustainability of the business?

\section{Notifying the affected party}

If corporate responsibility was critical in the previous stages, this stage expands even more on the need to unify values in the process of notifying the affected party of the decision. Some illuminating aspects to take into account include:

- Is communication with the affected party carried out individually, face-to-face and not over the telephone or by post?

Does the process of communicating the redundancy decision follow logical hierarchical channels, maintaining the necessary and appropriate level of confidentiality?

Is the affected person informed of the decision before non-managerial staff in their work environment?

- Is communication with the affected party carried out with sufficient time to attend to the individual correctly, paying minute attention both to methods and content of the communication?

- In what tone is the notification given and how is the individual treated?

- Is the reason for the redundancy decision communicated and justified in an honest and transparent manner to the affected person?

Does the affected individual receive a sympathetic and kind hearing?

Is the affected person given the opportunity to reply, defend themselves and, where appropriate, vent their anger?

- Who carries out the notification: the human resources manager, the direct line manager of the person affected, or someone else?

Is the affected party notified with sufficient time to allow them to adapt to the new situation?

- Is the moral and professional integrity of the individual preserved?
- Is the individual thanked for their services to the company?

Is effective support developed and offered openly to deal with the new situation and the search for alternative employment?

\section{The period of transition up to leaving}

This is the most critical period for individuals affected by redundancy and the organization, relationships with employees and customers, society's perspective and the organization's reputation. It must therefore be managed extremely carefully by exhibiting loyalty to individuals who have been and still are rightful members of the organization, understanding of the situation, empathy and generosity of treatment.

Many organizations demonstrate a high degree of suspicion or even fear during this transitional phase as they consider that it may damage the organization's interests. On occasions this can lead to them adopting hostile attitudes to the individual being made redundant. These attitudes can even lead to the company requesting that the individual leaves the company the following day, even though this involves paying the relevant compensation. Such a decision presupposes a cause and effect relationship of hostility and revenge towards the company and its managers by the individual being made redundant and involves on many occasions stripping the individual of their fundamental rights such as bidding farewell properly to colleagues, customers, suppliers, external partners etc. Of course, the redundant individual may interpret this as an aggressive attitude on the part of the organization, which only makes the situation worse.

Some of the possible considerations that the organization may bear in mind include:

- Are employment rights determined by legislation and those acquired as a result of belonging to the organization by the redundant individual being respected?

- Are the moral and professional integrity, the honour and good name of the affected individuals being protected and is honest and transparent communication being encouraged?

- Are the redundant individuals treated correctly at all times?

- Is sufficient time granted to the individual to leave the organization in the correct fashion, bidding farewell to customers, suppliers, external partners and colleagues?

Is the decision communicated openly and honestly to the rest of the organization, avoiding rumours and mistaken interpretations?

- Have relevant activities been put in place aimed at facilitating the exit and search for new employment?

- Is there an attempt to isolate individuals from the organization's remaining employees?

- Are redundant employees allowed to say goodbye and communicate with the organization's remaining employees?

Are redundant employees allowed to say their goodbyes in an appropriate way to customers, suppliers, external collaborators etc.? 
- Does the organization make itself available in order to explain the reasons for the decision to customers who are potentially affected by it?

\section{E. The point of leaving}

This stage encompasses the last moment of contact of redundant individuals with the organization and their exit from its property. During this stage, the following aspects may be considered:

- $\quad$ Are employment rights determined by legislation and those acquired as a result of belonging to the organization by the redundant individual being respected?

- Are exit interviews conducted before people leave to understand their perception both of the decision and the way that the process has been carried out?

- Is the individual treated with dignity, maximum respect and recognition for their services at the point they leave the company?

Do the managers with the closest relationship with the affected individuals proceed with the utmost respect, dignity and care towards them, bidding them farewell in correct fashion and being present in person?

\section{F. The period afterwards}

This period covers the time after the redundant individuals have left the company. During this stage, the following cognitive aspects may be considered

- Does the organization maintain contact with those made redundant and take an interest in their situation?

Does the company implement actions in support of their finding a new job?

- Do communications that allude to redundant employees, both within and outside the organization, safeguard their personal and professional integrity and their honour?

- Does the organization take appropriate actions such that the redundancy decision has no effect on the quality of service to customers or on relationships with suppliers or other allies?

\section{CONCLUSIONS}

In this study we have presented some general reflections about the possible ethical implications and ethical conflicts that a manager, with an ethical concern, might consider during the redundancy process. The aim has been to be orientative rather than prescriptive. Every organization has its own special circumstances and the way it chooses to behave will, without doubt, determine its ultimate direction. A critical aspect of this behaviour is the way the organization considers people: either as ends in themselves or as resources. In this context, the starting point for the study is the strong conviction that the ethical character of an organization represents the best perspective for an optimum interpretation within a realistic context, exploring cognitively the possible effects that its actions have or may have on individuals.

The study does not aim to pass judgement on the behaviour of organizations going through redundancy procedures. However, we should admit that we want to mobilise awareness within organizations and sound the alarm about specific aspects that companies or academic efforts in the area often fail to evaluate fully, with the result that they adopt a neutral and materialistic approach that is, in many cases, devoid of emotional and humane aspects.

\section{REFERENCES}

[1] Blowfield M., and Frynas, J.G,: 2005, 'Setting New Agendas: Critical Perspectives on Corporate Social Responsibility in the Developing World', International Affairs, 81 (3), pp. 499-513

[2] Boatright, J.R.: 2007, 'Ethics and the Conduct of Business'(5th edn.), (Pearson Prentice Hall, New Jersey)

[3] Clarkson, M.B.E.: 1995, 'A Stakeholder framework for analyzing and evaluating corporate social performance, Academy of Management Review, 20, pp. 92-117.

[4] Crane, A. Matten, D.:2007, 'Business Ethics' (2nd edn.), (Oxford University Press, Oxford)

[5] Datta, D. K., Guthrie, J. P., Basuil, D.,\&Pandey, A.: 2010, Causes and effects of employee downsizing: A review and synthesis. Journal of Management, 36(1), 281-348.

[6] De George. R.T.:2006, 'Business Ethics'(6th edn), ..(Prentice Hall, New Jersey)

[7] Denis, D. and Kruse, T.: 2000. Managerial Discipline and Corporate Restructuring Following Performance Declines, Journal of Financial Economics 55, 391-424.

[8] Freeman, R.E.: 1984, 'Strategic management: A stakeholder approach' (Pitman Publishing Inc., Boston).

[9] Hill, C.W.L. and Jones, G.R.: 2001, 'Strategic management: an integrated approach' (5th edn.). (Houghton Mifflin, Boston).

[10] Kozlowski, S.W.J., Chao, G.T., Smith, E.M., \& Hedlund, J.:1993, Organizational downsizing: strategies, interventios, and research implications', In C.L. Cooper and I.T. Robertson (Eds.), International review of industrial and organizational psychology, 8 (Wiley \& Sons, New York), pp. 263-332.

[11] Lange, D., \& Washburn, N. T. :2012,. Understanding attributions of corporate social irresponsibility. Academy of Management Review, 37(2), 300-326.

[12] Martín Castilla, J.I.: 2002, 'Posible Ethical Implications in the Deployment of the EFQM Excellence Model'. Journal of Business Ethics, pp. 39, 125-134.

[13] Tamari, M: 2000, 'Downsizing and Stakeholder Capitalism: A Jewish Perspective', Darché [On line] http://www.darchenoam.org/ethics/DSZ/DMTamari.htm

[14] Zingales, L.: 2000, 'In search of new foundations', Journal of Finance, 55, pp. 1623-1653. 